(C) 2015 IEEE. Personal use of this material is permitted. Permission from IEEE must be obtained for all other uses, in any current or future media, including reprinting/republishing this material for advertising or promotional purposes, creating new collective works, for resale or redistribution to servers or lists, or reuse of any copyrighted component of this work in other works. 


\section{That Flipping Classroom - Getting engineering students to be consciously competent on their own}

\author{
Robin Braun \\ School of Computing and Communications \\ University of Technology Sydney, Australia \\ Email: robin.braun@uts.edu.au
}

\author{
Zenon Chaczko \\ School of Computing and Communications \\ University of Technology Sydney, Australia \\ Email: zenon.chaczko@uts.edu.au
}

\begin{abstract}
We start by elaborating on our description of a learner setting out on any learning endeavour in terms of the $\mathbf{4}$ quadrant diagram[1]. Our exposure to complexity theory informs us, and in particular persuades us to add chaos into the centre of the diagram. We go on to show that "teaching" in a classroom situation really only moves the student from the unconsciously incompetent state to the consciously incompetent state. To be able to move from the incompetent side of the diagram, to the competent side requires student activity. It is our contention that facilitation of this activity is a far better use of teacher resources than content delivery. We go on to describe how we structure our subjects, 48740 and 48750 to enable this, and give an evaluation as to how well this succeeded in the Spring and Autumn semesters of $2014 / 15$.
\end{abstract}

\section{INTRODUCTION}

Do Engineering Students really get it? Perhaps we are referring to the 80:20 rule. The difficulty many students in engineering have in grasping difficult threshold concepts, and perhaps even basic ones. $20 \%$ get it, and $80 \%$ muddle through.

What should we be doing about it? Does it really matter? We still manage to produce enough technically competent engineers to push our society forward (or do we?) Can we really improve that $80: 20$ rule to perhaps 50:50? Is it our responsibility as educators to be doing that? Is it not perhaps the students who should be taking the responsibility for their own learning? In this paper we are going to explore how we can perhaps do it by changing our teaching style.

Many engineering educators have started to consider the "Flipped Classroom" mode as an alternative teaching style. We refer the reader to Willey[8], [10], [9] et. al. at UTS. We provide a rationale for its use. We base it on the "Four Stages of Competence" model by Noel Burch[2].

\section{THE STUdent AND the COMPLEX Plane}

\section{A. The Complex plane}

Let us begin by introducing a simplified view of the complex plane. The complex plain is referred to in many works, including those of authors such as John Holland[3], [4] of the Sante Fe Institute. In particular I refer the reader to the excellent small book by Neil Johnson[5]. I also refer the

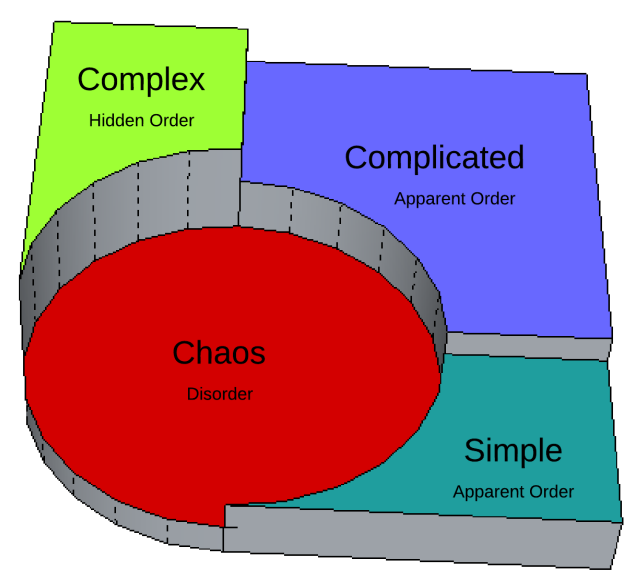

Figure 1. Simplified Complex Plain

reader to the work of Dave Snowden[6] and his "The Cynefin framework".

We like the diagram in Figure 1 as a way of simply explaining the complex framework.

On observing simple things one can see that they are ordered. Simple things can become chaotic. They can also become complicated. Generally complicated things are just simple things on a large scale. They too can become chaotic.

On the other hand, complex things may exhibit apparent order, but they also have hidden order. They have many other things including emergent properties. For example, an ant colony is complex. One of its most powerful emergent properties is its ability to survive adversity. Ant colonies can live for hundreds of years, and have existed for millions[7]. Complex things may also fall into chaos and disorder.

\section{B. Translation to the leaner model}

It occurs to us that this model of complexity can readily translate to the 4 quadrant model of a student. See Figure 2.

1) Simple translates to the Unconsciously Incompetent (UI) student. 


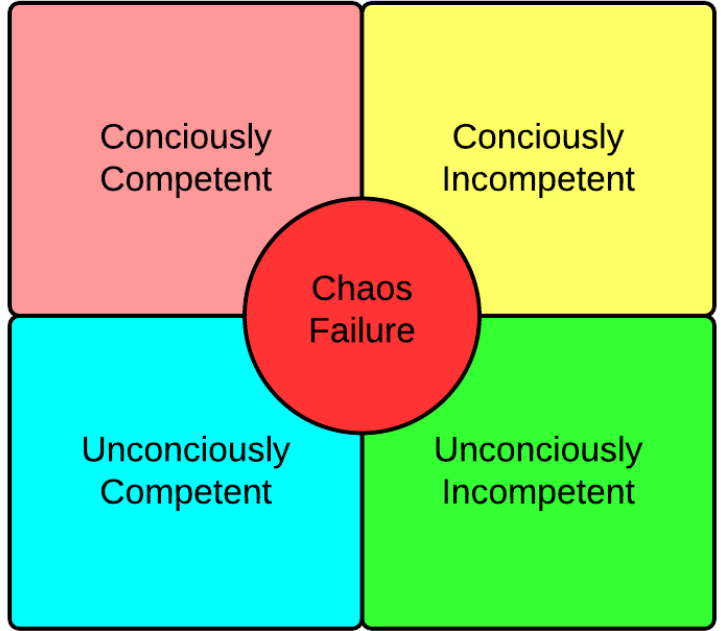

Figure 2. The 4 Quadrant model of a student - modified

2) Complicated translates to the Consciously Incompetent (CI) student

3) Complex translates to both the Consciously Competent (CC) and the Unconsciously Competent (UC) students.

4) Students in any of these states can fall into chaos. The chaos area prevents students from progressing diagonally across the diagram

\section{Conscience Competence learning matrix}

Noel Burch[2] first described the "Four Stages for Learning Any New Skill" in the 1970's. It has since been frequently attributed to Abraham Maslow, although the model does not appear in his major works.

The model suggests that individuals are initially unaware of how little they know, or unconscious of their incompetence.

Whilst they are learning they become able to understand their incompetence. They then consciously acquire a skill, and then consciously use it. As they become skilled in their field, their skill can be utilised without it being consciously thought through. This is the state of being inherently competent. The student has then acquired unconscious competence. This state can be reached after much experience and the gaining of wisdom.

\section{Use as a state transition diagram}

For the purposes of our explanation, we consider the four quadrants to be four possible states in which the student can be found. In general, the leaner enters the learning module in the UI state. Then movement to the other states is the intention of the learning process. All of this can be described as a state transition diagram with likelihoods of movement from one state to the next. The way that we design the educational process to modify the various likelihoods (probabilities) of movement is the subject of this paper. See Figure 3.

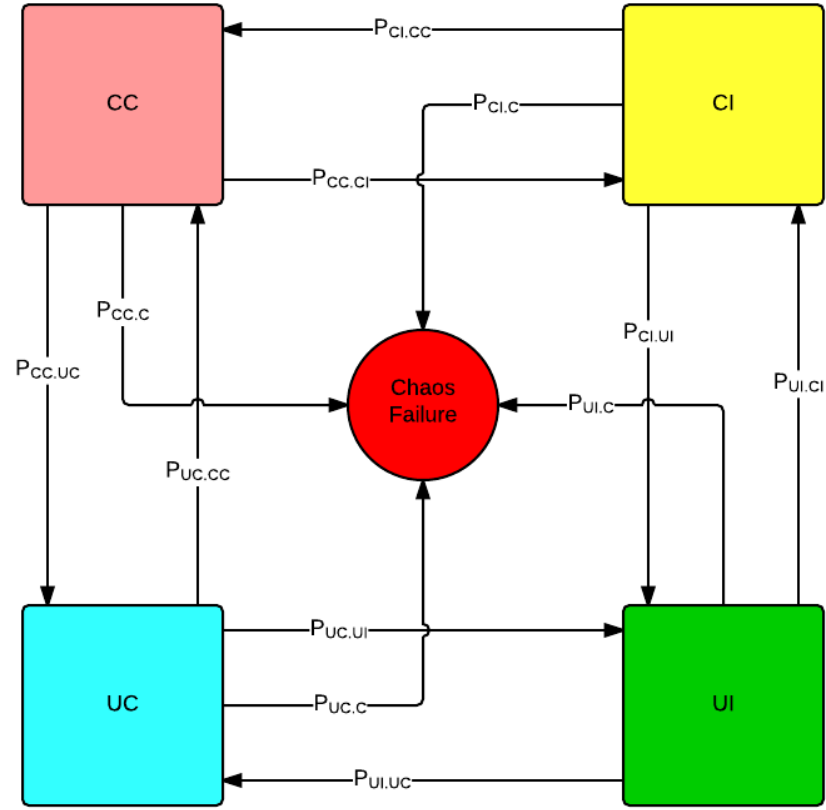

Figure 3. 4 Quadrant State Diagram

1) We can see that the probability of movement out of the UI state is

$P_{U I . E}=P_{U I . C I}-P_{C I . U I}+P_{U I . C}+P_{U I . U C}-P_{U C . U I}$

Transitions between the UI and the UC states are very unlikely in the case of a student module in higher education. These transitions do occur in cases such as children learning a language or learning to ride a bicycle. In our case we will set them to zero and ignore them. The equation therefore becomes;

$$
P_{U I . E}=P_{U I . C I}-P_{C I . U I}+P_{U I . C}
$$

2) The probability of movement out of the CI state is;

$P_{C I . E}=P_{C I . C C}-P_{C C . C I}+P_{C I . C}+P_{C I . U I}-P_{U I . C I}$

We want to maximise this probability through the design of the learning process. This means minimising $P_{C C . C I}$ through positive reinforcement and practice, and maximising $P_{C I . C C}$ through student centric classroom activity.

3) For completeness we include the probability of movement out of the CC state as follows;

$P_{C C . E}=P_{C C . U C}-P_{U C . C C}+P_{C C . C}+P_{C C . C I}-P_{C I . C C}$

We are not going to include these transition in our discussions. 


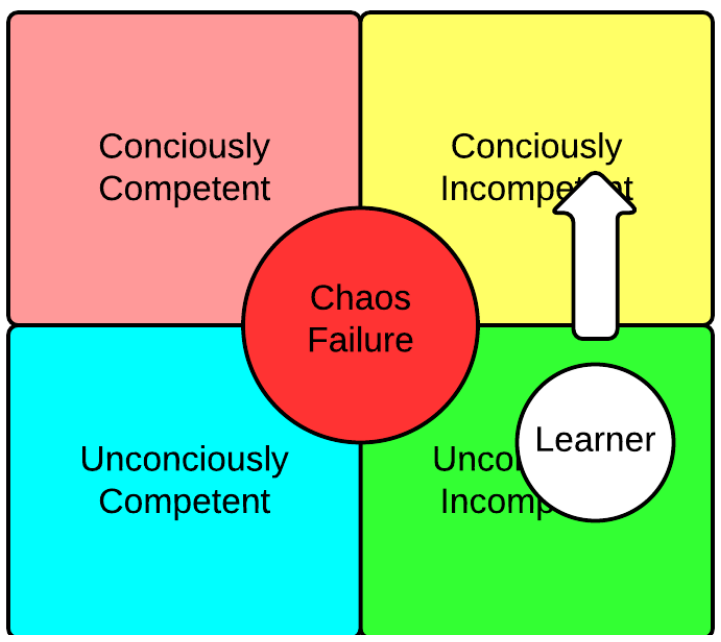

Figure 4. Movement from the UI state to the CI state

\section{How StUdents NAVIGATE THE STUdENT MODEL}

\section{A. Moving from being Unconsciously Incompetent to being Consciously Incompetent}

The likelihood of the movement out of the UI state and to the CI state is given in Equation 1. Traditional engineering education concentrates on this transition. It attempts to maximise $P_{U I . C I}$ while trying to minimise $P_{U I . C}$. Much of the effort of the lecturer has been aimed at minimising the chance of decent into chaos and failure, and maximising the probability of the student becoming Consciously Incompetent.

This was generally achieved by the lecturer teaching the learners who took notes and were otherwise passive. Mechanisms, such as online resources were not readily available for the learners to take responsibility for this step themselves. See Figure 4

Now that we have readily available IT systems, it is becoming feasible for learners to take responsibility for this themselves, but the framework must be carefully designed.

\section{B. Moving from being Consciously Incompetent to being Con- sciously Competent}

The likelihood of movement out of the CI state and to the CC state is given by $P_{C I . C C}-P_{C C . C I}$. In traditional engineering education this was achieved through the use of labs, tutorials and internships. At the University of Technology Sydney all engineering students do two managed six month internships in industry during their 5 year program. In fact, it is sometimes called a "co-opt" program because the University co-opts industry to help in the educational process by maximising the $P_{C I . C C}$ transition. Often the lecturer does not play a big part in this process. See Figure 5

This transition has less likelihood of descending into Chaos and Failure as most engineering learners have self selected

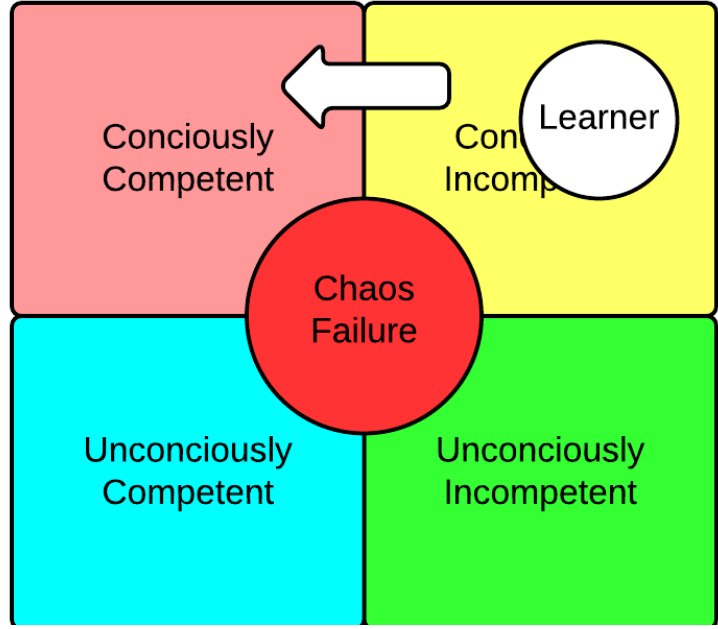

Figure 5. Movement from the CI state to the CC state

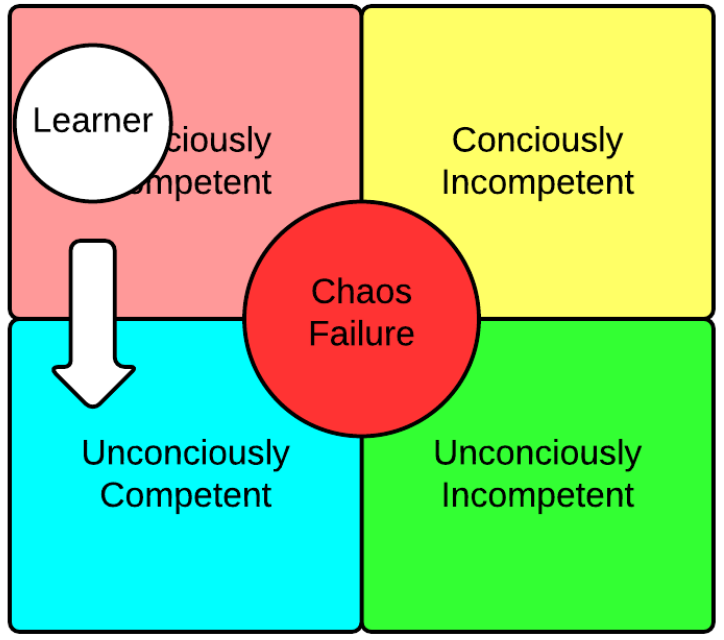

Figure 6. Movement from the Consciously Competent state to the Unconsciously Competent state

themselves to have technical competency and interest in their field of practice.

\section{Moving from being Consciously Competent to being Un- consciously Competent}

This transition comes from years of experience and lifelong learning, and generally comes after undergraduate education. We will not consider this in this paper. See Figure 6

\section{The chaos core}

Chaos and failure can be reached from any of the other states. It has many causes including personal ones, and ones that result from the design of the learning process. It is the duty of the institution, the lecturer and other academic staff to try to minimise the causes associated with the learning process, and where possible, the personal causes. See Figure 7 


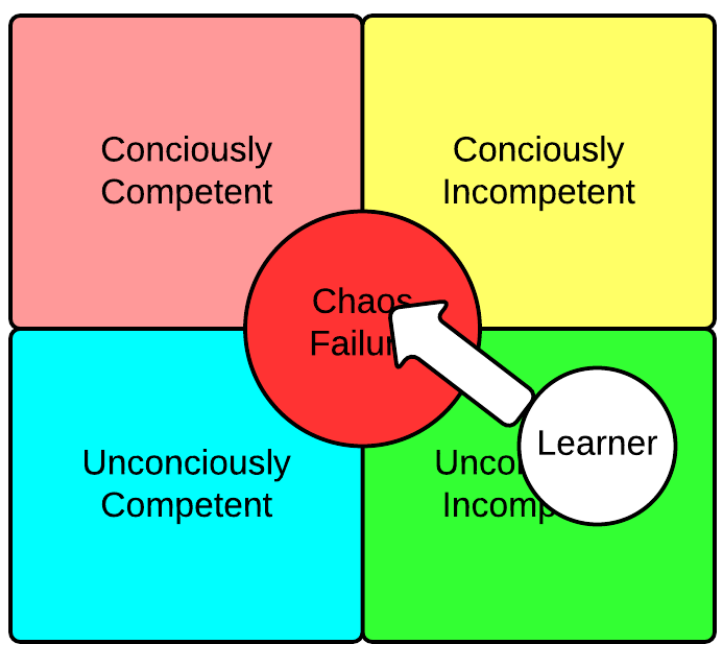

Figure 7. Descent into chaos

There are many ways in which the design of the teaching process can be used to minimise this. However, this is not the subject of this paper.

\section{TEACHING AND LEARNING}

\section{A. What happens when we "Teach"}

In traditional engineering education, students were taught. The centrepiece of any course was the classroom delivery of knowledge. It was the lecture. Even today, this is what students expect, and are very uncomfortable when they don't get this. Students and staff often talk of weekly lectures as apposed to weekly sessions which may include various kinds of learning activities. At best, teaching really only maximises the $P_{U I . C I}$ transition, that is really all can can be assessed effectively in examinations. Worse still, if the material is not internalised through other activities, the $P_{C I . U I}$ transition grows until it is equal to the $P_{U I . C I}$ transition and no long term transition is achieved.

This is only to prevalent. Students often comment that they have forgotten everything as soon as the exam is over.

Many studies have illustrated the effectiveness of student centred activities in moving students from the UI quadrant to the CI quadrant, and ensuring they do not fall back.

\section{B. What happens when we "Learn"}

By "Learn" we mean that students are doing it for themselves. By this we mean that they are doing it for themselves. They themselves are doing the activities that raise the value of $P_{U I . C I}$. They do the work of acquiring the resources they need to become Consciously Incompetent, setting themselves to make the transition to being Conciously Competent. See Figure 8

The state of being Consciously Incompetent is characterised by the learner being in possession of sufficient resources to

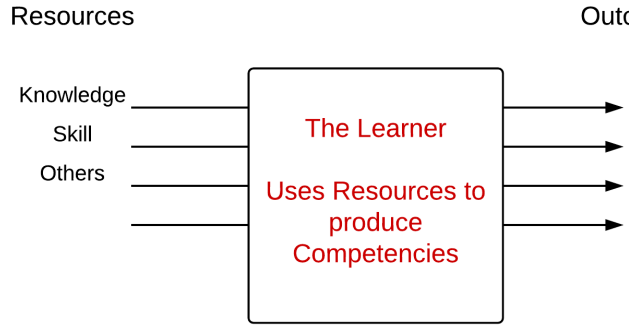

Figure 8. The resources mix

start to build competence, move to the Consciously Competent state. These resources may include;

1) Knowledge - the things that he or she knows

2) Skills - the way to do things. eg. Operate in a laboratory.

3) Others - many hidden or subconscious.

\section{Where does outcomes based education fit in?}

We can step back and consider what outcomes education did for us. Essentially it said, "Let us design our curriculum and subjects based on what competencies we expect from our learners, not what content they may require". Outcomes based education essentially says that knowledge and wisdom are very separate things.

- Knowledge is a resource

- Wisdom is an outcome

There are other resources that a learner needs in order to get to the LHS of the diagram. The Competent side. These would include Skill, Experience, etc. See Figure 8

\section{Outcomes and the 4 quadrant diagram}

In essence, Outcomes based education says that the degree to which the learner can enter the LHS of the diagram (the competent side) is not dependent on their IQ. It depends on the learning style, and the extent to which they can harness their resources.

To come back to our 4 quadrant diagram. The Outcomes measured in Outcomes Based Education show to what extent the learner has been able to enter the "Consciously Competent" quadrant. Movement to the "Unconsciously Competent" quadrant comes from experience, and the development of "wisdom".

\section{WHAT THEN IS FLIPPING IN THE CONTEXT OF MODERN ENGINEERING EDUCATION?}

From a historical point of view, Engineering Education was characterised by the content that was required in each subject. This lent itself to the model where the learners "received knowledge" from the lecturers by sitting passively in the classroom. Then it was hoped that they would internalise it and eventually become consciously competent in tutorials and labs 


\section{A. What this really means}

Flipping the classroom means completely removing responsibility for the knowledge (content) from the lecturer. This then frees up the lecturer to concentrate in moving the learner from "incompetent" to "competent". That is from the RHS to the LHS of the 4 quadrant diagram.

- And, being sure to prevent dipping into chaos, and

- as apposed to just moving the learner up the RHS

\section{B. Some pointers to making the classroom student centric}

1) Just in time knowledge: This all points to making the classroom student centric as apposed to lecturer centric. The students must do the work of acquiring knowledge. Unfortunately we still have to let students know the scope of what they need to know.

The idea of Just in Time JIT knowledge accumulation is very appealing, but implies that the student is already in the $2 \mathrm{nd}$ or 3rd quadrant. Students don't know what they don't know! It is a feature of being Consciously Competent when they are able to discover what they don't know.

2) Assessment: Students are driven by assessment, particularly if they believe that the assessment is Quantitive. (Get marks for it.) But what we really need is formative assessment. So, the trick is to make the assessment Formative, while the students think it is Quantitative.

3) From Knowledge to Resources: More and more we are thinking of knowledge as just another resource available to the practitioner. In earlier times, we would have thought of knowledge as being the end in itself. Once we accept this basis, we free up the student to consider the full range of resources available to their practice. These may include language, mathematics, knowledge, experience, etc.

4) From "content" to "competency": Make The students believe that they are becoming competent, as apposed to just knowing more. We often quiz new $\mathrm{PhD}$ candidates as to why they are doing a $\mathrm{PhD}$. Often we get the response that they are doing it so that they can get more knowledge, or a deeper understanding. Actually the $\mathrm{PhD}$ has some of that, but probably its biggest element is its intense ability to build competence in its graduates. It is often thought of as a journey into theory, but actually it is the most intense competence building excersise that we have. It is the one degree that we can be sure fundamentally changes the graduate.

\section{Our EXPerience in 48750 Network Management AND PLANNING}

\section{A. The weekly learning pattern}

The subject is made up of a 3 hours per week sessions which can include a lecture, a quiz and a lab component. In the past, the lecture was the "centrepiece" of the weekly sessions.

\begin{tabular}{|c|c|c|}
\hline Hour & Previous sequence & New sequence \\
\hline \hline 1 & Lecture & $\begin{array}{c}\text { Quiz on current } \\
\text { session's material }\end{array}$ \\
\hline 2 & $\begin{array}{c}\text { Quiz on previous } \\
\text { session's material } \\
\text { lecture components }\end{array}$ & Lab \\
\hline 3 & Lab Table I \\
\multicolumn{2}{|c|}{ CHANGED WEEKLY PATTERN }
\end{tabular}

The quiz was on the previous week's material, and the lab was an ongoing weekly sequence of projects which include simulations and emulations.

Now the lecture no longer has the same importance in the new structure. Previously it was used to present knowledge, discuss difficult aspects and provide motivations for various aspects.

The quiz is structured as an assessment task that carries $25 \%$ of the final mark.

- The quiz is on the current session's material, and occurs before any of that material is "lectured".

- The quiz is not "open book".

- This forces them to engage with the material before arriving for the quiz.

- Students who get more than $85 \%$ for the quiz's can choose to use their quiz mark as their final exam mark

- This further motivates them to engage with the material before classroom activity.

- The quiz's are done online in the computer lab with a password.

- Students do not have the option to redo the quiz.

\section{B. The value of the quiz's}

The quiz structure is designed to persuade the students to study the material before it is reinforced in Tutorial/Lecture period. Hopefully in this way, they get themselves into the CI quadrant. Then the Tutorial/Lecture starts to move them to the CC quadrant.

\section{The value of the tutorials/lecture}

This session is designed to help the student move from the CI to the CC quadrant as regards that session's goals. It is structure as tutorial questions with the solutions only being visible after the question has been attempted. Interspersed with these are short 10 minute lectures on key topics that may have been difficult for the student in their personal study. The solutions to the tutorial problems are presented as richly commented Matlab code, which are also "talked through" via a short 10 minute videos.

\section{The labs}

The lab is designed to further consolidate the student's movement from the CI quadrant to the CC quadrant. The students 
have to complete 3 significant projects. The first is a emulation of a teletraffic situation. The second is a simulation of a packet queueing system. The third is an optimisation based on the Population Based Incremental Learning algorithm.

\section{CONCLUSIONS}

The "experiment" has now run twice. First was on the subject 48750, Network Planning and Management. The second was on the subject 48740, Communications Networks. Therefore, the sample is too small to report any significant statistics. However, a number of comments can be made.

As regards learning outcomes. It is very apparent that the cohort is significantly more competent at the end of the subject than before. This is reflected in the average mark which increased from about $63 \%$ to $69 \%$.

As regards the student response. The students hate it. Many of the comments suggest that they feel they are doing all the work and the lecturer is not doing any. (Perhaps this suggests that there is method in the madness!) In reality, our experience is that this structure has certainly not decreased our workload. We are working harder at different things.

Will we continue this model? Yes, certainly. We will develop and refine it.

\section{REFERENCES}

[1] Keynote speech. "That Flipping Classroom”, ITHET 2014, Sep 11-13, York, UK

[2] Noel Burch, "Four stages of competence", http://en.wikipedia.org/wiki/Four_stages_of_competence as referenced on $01 / 04 / 2015$.

[3] John Holland, "Hidden Order: How Adaptation Builds Complexity", Perseus Books, 1996

[4] John Holland, "Emergence: From Chaos To Order", Helix Books, 1999

[5] Neil Johnson, "Simply Complexity: A Clear Guide to Complexity Theory", Oneworld Publications, 2010

[6] Dave Snowden, http://en.wikipedia.org/wiki/Cynefin as referenced on the $01 / 04 / 2015$.

[7] John and Sarah free materials (c), Interesting facts about ants, http://lingolex.com/ants.htm, 1996

[8] Willey, K. \& Gardner, "Combining flipped instruction and multiple perspectives to develop cognitive and affective processes." , A.P. 2014

[9] Gardner, A.P., Willey, K., Vessalas, K. \& Li, J. 2014, "Experiences with flipped learning in subjects in consecutive stages of aCivil Engineering programme", School of Engineering \& Advanced Technology, Massey University, Turitea Campus, Palmerston North 4442, Wellington, NZ.

[10] Willey, K. \& Gardner, A.P. 2014, 'Impact of students goal orientation in a flipped learning environment', School of Engineering \& Advanced Technology, Massey University, Turitea Campus, Palmerston North 4442 . 